\title{
Bridging Innovation to Prevent Ventilator-Associated Pneumonia: A Descriptive Qualitative Study among Critical Care Nurses
}

\author{
Yulis Setiya Dewi ${ }^{1^{*}} \odot$, Arina Qona'ah ${ }^{1} \odot$, Hidayat Arifin ${ }^{2} \odot$, Rifky Octavia \\ Pradipta $^{1} \odot$, Rosita Rosita ${ }^{1} \odot$, Lizy Sonia Benjamin ${ }^{3} \odot$ \\ ${ }^{1 *}$ Faculty of Nursing, Universitas Airlangga, Surabaya, Indonesia \\ 2Department Medical Surgical Nursing, Faculty of Nursing, Universitas Padjadjaran, \\ Indonesia \\ ${ }^{3}$ College of Nursing, King Khalid University, Abha, Kingdom of Saudi Arabia
}

\begin{abstract}
Background: Ventilator-Associated Pneumonia (VAP) is still a concern for individuals who are dependent on a ventilator. It is envisaged that the growth of technology-based innovations would lead to the creation of remedies for the prevention of VAP.

Purpose: The purpose of this study was to learn more about ICU nurses' perspectives on nursing innovations to avoid VAP in patients who are on ventilators.

Methods: Throughout July and August of 2021, a descriptive qualitative research study was conducted. Through the use of the snowball sampling approach, a total of 30 critical care nurses were recruited. During the interview procedure, each participant had around 40 minutes of time for an in-depth interview using a semi-structured format. In order to analyse the findings of the interviews, the technique proposed by Colaizzi was used.

Results: The following four themes emerged: 1) Development of tools to prevent infection, 2) Innovation to monitor cuff tension, 3) Improvement of nurses' skills and knowledge in using technology, and 4) Nurses' burden in using technology.

Conclusion: Nurses may benefit from considering VAP management as a part of technology-based innovation strategy. Nurses have praised the invention for measuring and monitoring the ETT cuff as a source of optimism for future advancement.
\end{abstract}

Gopen access

Jurnal Keperawatan
Padjadjaran (JKP)

Padjadjaran (JKP)

Volume 9(3), 232-239

(C) The Author(s) 2021

https://doi.org/10.24198/jkp.

v9i3.1923

Article Info

Received : November 20, 2021

Revised : December 16, 2021

Accepted : December 23, 2021

Published : December 29, 2021

Corresponding author

Yulis Setiya Dewi

Faculty of Nursing, Universi-

tas Airlangga, Surabaya, In-

donesia, Postal address: 60115 ,

Phone: 62 83854006001, E-mail:

yulis.sd@fkp.unair.ac.id

Citation

Dewi, Y.S., Qonaah, A., Arifin,

H., Pradipta, R.O., Rosita., \&

Benjamin, L.S. (2021). Bridging Innovation to Prevent Ventilator-Associated Pneumonia:A Descriptive

Qualitative Study among Critical

Care Nurses. Jurnal Keperawatan

Padjadjaran, 9(3), 232-239.

https://doi.org/10.24198/jkp.

v9i3.1923

\section{Website}

http://jkp.fkep.unpad.ac.id/index. php/jkp

This is an Open Access article distributed under the terms of the Creative Commons Attribution-NonCommercial 4.0 International License.
Keywords: innovation; Ventilator-Associated Pneumonia; nurses; critical care; ventilator.

\section{Introduction}

The increased risk of nosocomial infection is one of the issues confronted by patients treated in the intensive care unit (ICU) (Kózka et al., 2020), and one of them is Ventilator-Associated Pneumonia (VAP) in the lower respiratory tract. Because of the increasing morbidity caused by VAP, it is necessary to make comprehensive measures to address the problem. There are a variety of variables that contribute to VAP, including poor infection management and the transfer of microorganisms from the exterior environment to the internal environment (Bacterial Translocation) (Vance et al., 2010). VAP occurs in $5-40 \%$ of patients on invasive mechanical ventilation for more than two days (Atashi V Mahjobipoor H, Yazdannik A.Atashi, Vajihe, 2018). High rate of mortality is the most serious danger of this case, with VAP reaching 70 percent in some cases (Torres et al., 2017) and the incidence of VAP in the ICU is about $5-15 \%$ of total patients (Klompas et al., 2014). Proper VAP prophylaxis can shorten the length of a patient's hospital stay, cut treatment costs, and improve patient satisfaction (Samra et al., 2017).

Nurses have a crucial role in determining the overall quality of healthcare services (Koch et al., 2020). The abilities of nurses in nursing care, as 
well as preventative actions, are extremely essential variables in reducing the likelihood of problems. It is necessary to provide complicated observation and therapy, as well as high-intensity intervention and constant monitoring in the intensive care unit (Vance et al., 2010). The goal of today's nursing care is to reduce the likelihood of problems such as bacterial translocation and micro aspiration in the airways.

Nursing innovations in the prevention of VAP in patients who are on ventilators need to be a concern (Osti et al., 2017). The majority of causes of VAP occurred due to environmental factors, nosocomial infections, and nurses (Divatia et al., 2020). In addition, given the sheer number of nurses' duties, the success of the Endotracheal Tube (ETT) is rarely performed well. It also causes VAP. For this reason, nursing innovations to detect the causes of VAP need to be developed. However, the innovation to prevent VAP that is easy to monitor is not yet to be developed in Indonesia. Thus, in this study, we explored nurses' perceptions of the incidence of VAP in ETT-fitted patients to bridge innovation. We focused on the ETT because it is directly connected to the patient's respiratory tract and is highly susceptible to VAP. For this reason, a qualitative approach was taken to explore the innovations needed by nurses in the ICU to prevent VAP among patients with ventilators.

\section{Methods}

\section{Study design}

This study used a descriptive qualitative design. This approach aims to explain all conditions and circumstances as they currently exist, including what is still occurring or being carried out at the time of the research (Polit \& Beck, 2012).

\section{Settings and Participants}

The study was conducted in the Intensive Care Unit (ICU), Government and Educational Hospital in Surabaya, Indonesia. The data was taken from July to August 2021. The subjects were obtained using snowball sampling. We partnered with the Nurse Unit Manager (NUM) to gather participants with the inclusion criteria who were nurses in the ICU, worked more than one year and had clinical privileges to treat patients on ventilators from the hospital. Thirty participants were recruited using purposive sampling technique.

\section{Ethical Consideration}

We gained ethical permission from the Haji Surabaya Hospital Ethics Committee (No. 073/16/ KOM.ETIK/2021) and the Universitas Airlangga Hospital Ethics Committee (No. 154/KEP/2021) of the Health Commission of Indonesia. Participants were asked to provide written agreement before taking part in the study, and they were not obliged to do so under duress. They had the option to withdraw from the research without providing a reason, with no ramifications for their health care, and they also had the option to refuse to answer any of the questions. The researchers also made every effort to safeguard their anonymity during the whole interview session. All of the data was deidentified throughout the transcription process, with individuals being identified by numbers such as $\mathrm{P} 1, \mathrm{P} 2$, and so on, rather than using their names.

\section{Data Collection}

To gather information from critical nurses, four researchers performed an in-depth interview. Three interviewers performed for each seven participants and one reviewer performed for nine participants. Because of the COVID-19 Pandemic in Indonesia, and because the highest incidence was expected in the middle of 2021, we conducted our interviews via online meeting using Zoom Application. The researchers were health-care professionals with competence in critical nursing and medical surgical nursing departments, as well as previous experience doing qualitative research in these fields. There was no personal link between any of the study participants and any member of the research team.

In order to participate in the study, we asked permission to record the Zoom conference without video and audio only, which was granted. All of the recorded interviews were preserved in the Zoom application and only the researcher able to access them in order to maintain confidentiality. A clinical nurse who worked in an intensive care unit provided insight for the interview questions, and the researcher used that insight to develop the interview guidelines. The information was gathered through an interview with four experts (one expert in the critical nursing department, one medical doctor with a specialization in intensive care, and two nursing managers in the hospitals) before it was sent to participants. We conducted interviews with three critical nurses in order to determine the validity and reliability of the substance of the questions. Following that, we noted which questions were difficult for participants to grasp and updated them accordingly.

Furthermore, each researchers provided an explanation of the research aims to participants. For example, "How did you learn about VAP?" and "Can you tell me, what is your goal for innovation tools to prevent VAP?" were among the questions asked during the interview process. "Please tell us about your burden to employ innovation?" was another question. A total of around 40 minutes was spent to interview each of the participants. The interview was conducted using Bahasa Indonesia. After the interview procedure was completed, all researchers conducted an overall interview online. The researcher then re-confirmed with the participants about any information that was still unclear and instructed them on how to obtain the proper information. The interview was triangulated in order to improve the quality of the data using interview investigator triangulation (Heath, 2015). 
When the data set achieved saturation, the process of recruiting new participants came to an end.

\section{Data Analysis}

It was necessary to use Microsoft Word 365 to complete the transcribing and verbatim operations. Following that, the researchers coded and evaluated their findings with the help of the NVIVO 12 program (QSR International). A group discussion forum amongst the four researchers was organized in order to bring the perceptions of the four researchers closer together. As a result, they will have the same viewpoint and will be able to decide the theme of the investigation. The approach developed by Colaizzi was employed in the analysis of the interview findings. (1) Familiarization with the transcript, (2) identification of significant statements, (3) formulation of meanings, (4) clustering of themes, (5) development of detailed description, (6) production of the fundamental structure, and (7) seeking verification of the fundamental structure were the stages involved (Morrow et al., 2015). The researchers used the Standards for Reporting Qualitative Research to improve the quality and transparency of the study results and the reporting that went along with them (SRQR) (O'Brien et al., 2014). Trustworthiness used credibility, transferability, confirmability, and dependability (Korstjens \& Moser, 2018; Lincoln \& Guba, 1985).

\section{Results}

\section{Demographic Study}

From 30 critical care nurse participants, the average age is 31.8 years with the majority of female
$(80 \%)$. The work status of nurses is roughly the same between government servants and non-civil servants. Almost half (46.6\%) of the total participants have education of diploma in nursing level and work in non-COVID-19 ICU rooms. On average, participants worked as nurses for 8.8 years and as critical nurses for 5.5 years (Table 1 ).

\section{Constructed Themes}

From this study, we got four major themes that describe innovations in patients with ventilators to prevent VAP. The four are 1) Development tools to prevent infection, 2) Tension cuff monitor innovation, 3) Improving nurse's skills and knowledge in using technology, and 4) Nurse's burden in technology use (Table 2).

\section{Theme 1: Development tools to prevent infection}

According to the findings of this study, nurses have high expectations for technology advancements in nursing interventions to prevent VAP. We get the theme of Development tools to avoid infection, which is supported by three categories: 1) Easy to use, implement, and maintain, 2) Connectedness, and 3) Real-time and digital-based applications.

\section{Easy to use, implement, and maintain}

In developing nursing innovations to prevent VAP, innovations that are easy to use, install, and maintain are the focus of attention for nurses. This is because nurses can use these innovations if there is a rotation or shift change of nurses. This is contained in the following statement:

"of course... current inventions must be simple

Tabel 1 Participants Characteristics $(n=30)$

\begin{tabular}{lc}
\hline \multicolumn{1}{c}{ Characteristics } & $\mathbf{n}(\%)$ \\
\hline Participants age (mean) & 31.8 years \\
Gender & $6(20)$ \\
Male & $24(80)$ \\
Female & \\
Job status & $14(46.6)$ \\
Civil servant & $16(54.4)$ \\
Non civil servant & \\
Education Level & $14(46.6)$ \\
Diploma in Nursing & $15(50)$ \\
Bachelor/Professional in Nursing & $1(43.3)$ \\
Master in Nursing & \\
Workplace & $28(93.3)$ \\
ICU Non-COVID-19 & $2(6.6)$ \\
ICU COVID-19 & \\
Length of work & 8.8 years \\
As nurses & 5.5 years \\
As critical nurses &
\end{tabular}


Original Article

Dewi, Y.S., et al. (2021)

Table 2. Themes distributions

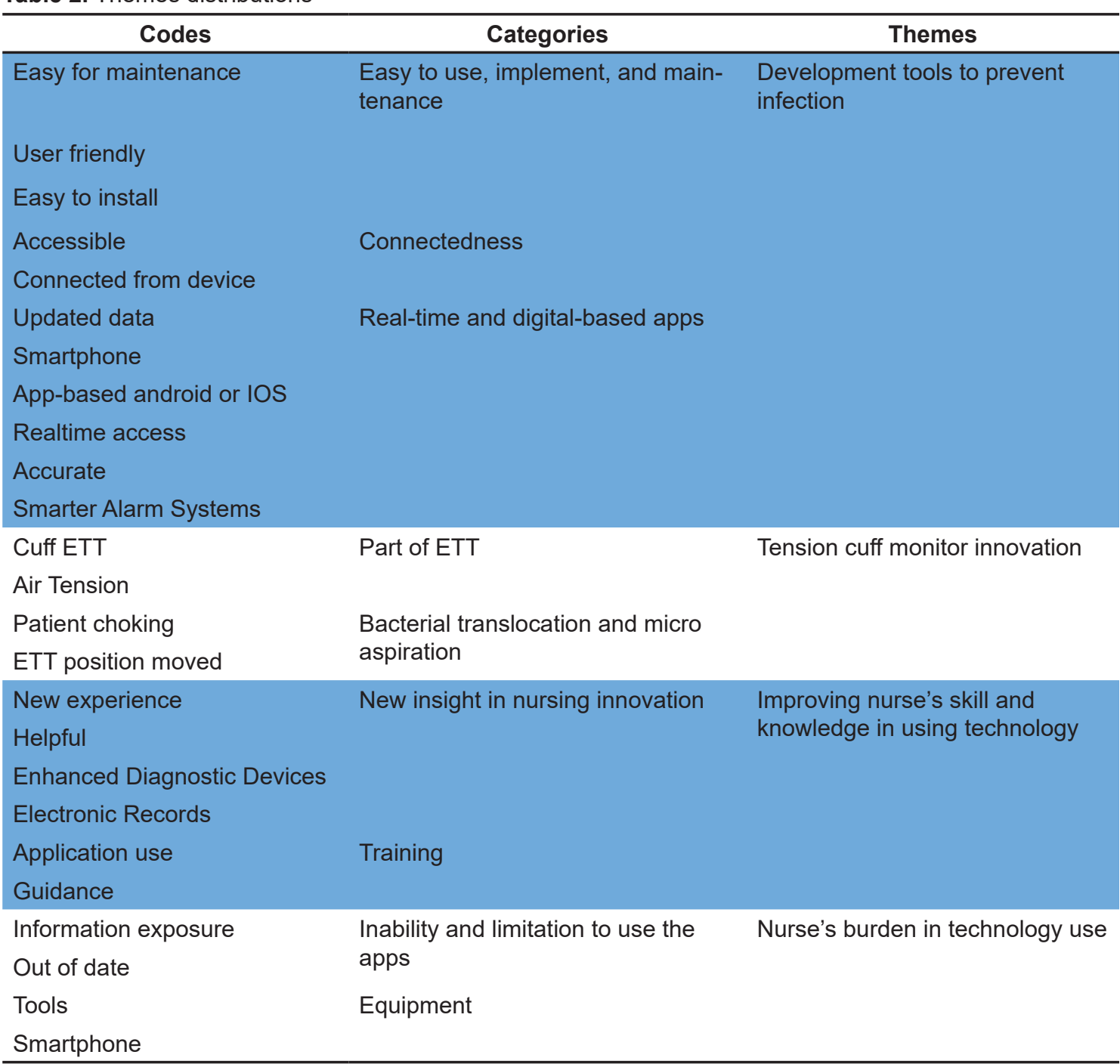

to use, simple to execute, and simple to set up and maintain." (P4)

"Hopefully, this invention will be of assistance and will make the task of nurses easier. However, it should be simple to use. Because not all of the nurses in this room are able to utilize such a program" (P10).

\section{Connectedness}

We found that nurses with innovation can help nurses working in controlling and preventing VAP in patients on ventilators. Existing innovations must be easily accessible and can be connected with the nurse's devise. This makes monitoring easier. The statement can be seen below:

"I've been a nurse in the ICU for a long time, but haven't found any innovations that can help us work. Especially for infection control in patients who are on a ventilator, it is difficult. And if there is an application that can connect to my smartphone or ICU room smartphone, it will certainly be very helpful. So all health workers such as doctors and nurses can make their work easier..." (P14).

\section{Real-time and digital-based apps}

Application-based innovations on Android and smartphones are currently attracting a lot of attention. Not only common people, nurses who work in the room also expect existing innovations to make the work of nurses easier. Innovation can be used to help securing data, can be applied to smartphones, and it is based on Android or IOS which can provide information or alarms as well as disturbances to patients and most importantly the innovation must be accurate. This can be seen in the following sentences:

"if there is an application that can monitor or prevent VAP that can be accessed with a smartphone at any time it will definitely make our work in the ICU easier..." (P22)

"most importantly, it must be accurate... it's useless to have innovation but it's not accurate... or the results are unclear. And if it can be accessed from anywhere and anytime, it will definitely make the job easier..." (P4). 
Theme 2: Tension cuff monitor and innovation

The nurse mentioned that there were frequent problems related to the ETT cuff. So that innovation is needed to carry out periodic and real-time monitoring. This theme is composed of two categories: 1) part of the ETT and 2) bacterial translocation and aspiration.

Part of Endo-Tracheal Tube

The nurse said that the ETT installed in the patient often experienced problems such as changing positions, and the ETT tension which was often not monitored. This is in the following sentence:

"In my opinion, what is often overlooked is the ETT cuff issue... even though it is very important. If the pressure is reduced, the ETT tube can move (up or down). But sometimes this is often forgotten..." (P9).

"Sometimes I forget that... often I miss checking the pressure in the ETT cuff. If there is an innovation that can help check it can be very helpful..." (P13).

Bacterial translocation and micro aspiration In this study, we found that according to nurses, VAP could occur due to bacterial translocation and micro aspiration of fluids from the mouth. It can be characterized as the patient is choking and the ETT position changes due to reduced ETT cuff tension. This can be seen in the following sentences:

"In terms of cleanliness from nurses, we always maintain personal hygiene before patients such as washing hands and using PPE. We always take care of this to reduce nosocomial infections. But it seems, the VAP can occur due to the lack of ETT pressure. If the tension in the ETT cuff is not strong enough, then bacteria can enter from the mouth and go down (throat). The patient may also choke... Maybe that should be a concern too..." (P10).

Theme 3: Improving nurse's skill and knowledge in using technology

The improvement of nurses' skills and knowledge in the use of technology can be increased by very informative and helpful innovations. This theme is supported by two categories, namely 1) New insight in nursing innovation, and 2) Training,

\section{New insight in nursing innovation}

With new innovations in nursing interventions, it can help and provide new insights for nurses and provide new innovative experiences. Of course this can help and facilitate the work to prevent the occurrence of VAP. Not only that, existing innovations can also assist in establishing a diagnosis in the VAS and can assist in medical records. This statement can be seen below:

"It will definitely be a new experience for us... because previously there were no innovations used to prevent infection. If there is, it will definitely help our work and have a positive impact on patients" (P17).

"If the innovation can help establish a diagnosis related to infection, it would be great. And it can also be medical records related to infection data in the patient's progress record. And maybe the innovation or the device can be installed in the ETT hose maybe... because usually the ETT cuff often lacks tension" (P4)

\section{Training}

Training related to the use of innovations to be developed is very much needed. It aims to improve the ability of nurses to use and operate these innovations. This statement can be seen in the sentence below:

"But before that (innovation), we also need to be guided, given information regarding how to use it. So we can have the same understanding to use the application. Moreover, there are not only nurses in the ICU... there are doctors and nurses. So training for doctors and nurses is also important..." (P25).

\section{Theme 4: Nurse's burden in technology use}

In this study, we found that nurses have their own burdens when it comes to using technology-based innovations. This theme consists of two themes, namely 1) Inability and limitations to use the apps and 2) Equipment.

Inability and limitation to use the apps

The limitations and inability of nurses in using internal applications as innovations for the development of innovations in the prevention of VAP can be seen from the dissemination of information that is less and outdated in the use of technology. This can be seen in the following sentence:

"the burden is clear if you have to use innovation or application. I'm old... can't use a smartphone anymore. If other people say, I'm out of date. Unlike the young children. But I can learn... slowly... can't be fast like other people" (P28)

"When it comes to applications on smartphones, I'm already dizzy... I'm old... I don't understand. But if possible, the innovation must be easy to use" (P4) Equipment

Nurses are worried about the equipment that will be used such as smartphones for the development of VAP prevention innovations. This can be seen in the following sentences:

"I'm confused.. my handphone is old... is it possible? If that's the case, then I think about it. what should I do? If I have to change my handphone, I have to spend more money. Not to mention I'm confused and can't use it" (P30).

\section{Discussion}

In According to the findings of this study, nurses must be more creative in their interventions. This study found that preparations must be made before innovation can be implemented in order to prevent VAP in patients on ventilators. The themes identified included the development of infection-prevention tools, innovation of tension cuff monitor, improving nurse skills and knowledge, and reducing the burden 
on nurses when using technological advances.

The first theme identified by this research is the development of technologies to help people avoid becoming infected. Technology-based improvements that can undoubtedly ease the job of nurses in a variety of areas, from monitoring and assessment to the prevention of VAP, are now being developed (Huter et al., 2020; Powell-Cope et al., 2008). However, the most important thing to remember is that the innovations made must be precise and able to be assessed precisely. A user-friendly, easy to install, and maintain program would also be a very useful factor in this case (Huter et al., 2020). In prior research, it has been found that nursing innovation interventions improve the efficiency of nurses' work while also reducing the responsibilities placed on nurses' shoulders (Kerr et al., 2020; Kong, 2009). But it is also possible to lower the frequency of infection in a continual manner for both nurses and patients, thanks to technologies that are focused on infection control. A major concern should be that the innovations generated are in accordance with the needs and are suitable, and that they assist patients, nurses, and other health-care professionals.

The nurses who spoke about EBP in the condition of patients with ETT were the next topic discovered in this study, according to the findings. Micro aspiration and translocation from the mouth into the respiratory system have both been implicated in the development of VAP (Akbiyik et al., 2021; Fromentin et al., 2021). The case is due to the low voltage of the ETT cuff. As a result, it is necessary to develop an innovative method of monitoring the ETT cuff. According to previous study, the occurrence of VAP is not only caused by environmental and hygienic factors, but also as a result of nurses' failure to regulate and maintain the cleanliness of patients who have ETT implanted (Divatia et al., 2020; Haque et al., 2018). This is why the creation of this intervention may serve as a recommendation in the future, making it easier for nurses to regulate ETT cuff pressure and avoid VAP while also serving as a reminder to them in the present.

Furthermore, technology-based innovations can provide new insights for nurses, increase knowledge, and skills in providing nursing interventions. The results of previous studies indicate that with technology-based innovations as well as being innovative and application, it can increase the knowledge and skills of nurses (Asurakkody \& Shin, 2018; Barchielli et al., 2021). However, with training related to the use of innovative technology that will be developed, nurses need to equalize perceptions and abilities in using these applications. This needs to be done because the health workers who will use the application are not only nurses, but also multidisciplinary health sciences.

However, nurses also conveyed the perceived burden of using technology-based innovation. This is due to the diversity of knowledge, abilities, and facilities owned by nurses. Previous research has stated that older aged nurses will experience limitations in following technological innovations in the implementation of nursing care (Pepito \& Locsin, 2019). For this reason, training, information dissemination, and introduction of innovations are needed. Thus, generalization of knowledge can be achieved.

\section{Strength and Limitation}

This study provides information related to the development of technology-based innovations in handling VAP. Not only that, the research presents EBP-based information submitted by nurses for the development of technology-based innovations. However, the diversity of research areas can be done to obtain more comprehensive information and it is necessary to consider the innovation needs of nurses working in rural areas.

\section{Conclusion}

It is possible that the development of technologybased improvements in nursing interventions to treat VAP in patients on ventilators will be taken into account in the future. Input that is based on Evidence-Based Practice supplied by nurses for the development of improvements in monitoring Cuff ETT pressure to avoid VAP utilizing apps-based applications is a valuable contribution to the field. The findings of this study may be useful to nurses and other stakeholders in the development of novel innovation using technology to overcoming VAP difficulties in the future. It also becomes the suggestion and information for hospital and nursing manager to develop innovation to prevent VAP among patients with VAP.

\section{Consent for publication \\ Not Applicable.}

\section{Availability of data and materials}

The data sets used and/or analysed during the current study are available from the corresponding author on reasonable request.

\section{Competing interests \\ None}

\section{Funding}

Ministry of Education, Culture, Research, and Technology of Republic Indonesia, No. 275/ UN3/2021.

\section{References}

Akbiyik, A., Hepçivici, Z., Eşer, I., Uyar, M., \& Çetin, P. (2021). The effect of oropharyngeal aspiration before position change on reducing the incidence of ventilator- associated pneumonia. European Journal of Clinical Microbiology \& Infectious Diseases, 40(3), 615-622. https:// 
Bridging Innovation to Prevent Ventilator-Associated

doi.org/10.1007/s10096-019-03789-4

Asurakkody, T. A., \& Shin, S. Y. (2018). Innovative behavior in nursing context: A concept analysis. Asian Nursing Research, 12(4), 237244. https://doi.org/10.1016/j.anr.2018.11.003

Atashi, V., Yousefi, H., Mahjobipoor, H., \& Yazdannik, A. (2018). The barriers to the prevention of ventilator-associated pneumonia from the perspective of critical care nurses: A qualitative descriptive study. Journal of Clinical Nursing, 27(5-6), e1161-e1170. https://doi.org/10.1111/ jocn. 14216

Barchielli, C., Marullo, C., Bonciani, M., \& Vainieri, M. (2021). Nurses and the acceptance of innovations in technology-intensive contexts: the need for tailored management strategies. BMC Health Services Research, 21(639). https://doi.org/10.1186/s12913-021-06628-5

Divatia J.V., Pulinilkunnathil J.G., \& Myatra S.N. (2020). Nosocomial Infections and VentilatorAssociated Pneumonia in Cancer Patients. In: Nates J., Price K. (eds) Oncologic Critical Care (pp. 1419-1439). Springer, Cham.

Fromentin, M., Ricard, J.-D., \& Roux, D. (2021). Respiratory microbiome in mechanically ventilated patients: a narrative review. Intensive Care Medicine, 47(3), 292-306. https://doi.org/10.1007/s00134-020-06338-2

Haque, M., Sartelli, M., McKimm, J., \& Abu Bakar, M. Bin. (2018). Health care-associated infections \&ndash; an overview. Infection and Drug Resistance, 11, 2321-2333. https://doi. org/10.2147/IDR.S177247

Heath, L. (2015). Triangulation: Methodology. International Encyclopedia of the Social \& Behavioral Sciences, 639-644. https://doi. org/10.1016/B978-0-08-097086-8.44059-6

Huter, K., Krick, T., Domhoff, D., Seibert, K., WolfOstermann, K., \& Rothgang, H. (2020). Effectiveness of digital technologies to support nursing care: Results of a scoping review. Journal of Multidisciplinary Healthcare, 13, 1905-1926. https://doi.org/10.2147/JMDH. S286193

Kerr, D., Ratcliff, J., Tabb, L., \& Walter, R. (2020). Undergraduate nursing student perceptions of directed self-guidance in a learning laboratory: An educational strategy to enhance confidence and workplace readiness. Nurse Education in Practice, 42. https://doi.org/10.1016/j. nepr.2019.102669

Klompas, M., Branson, R., Eichenwald, E. C., Greene, L. R., Howell, M. D., Lee, G., Magill, S. S., Maragakis, L. L., Priebe, G. P., Speck, K., Yokoe, D. S., \& Berenholtz, S. M. (2014). Strategies to prevent ventilatorassociated pneumonia in acute care hospitals: 2014 update. Infection Control \& Hospital Epidemiology, 35(8), 915-936. https://doi. org/10.1086/677144

Koch, P., Zilezinski, M., Schulte, K., Strametz, R., Nienhaus, A., \& Raspe, M. (2020). How perceived quality of care and job satisfaction are associated with intention to leave the profession in young nurses and physicians. International Journal of Environmental Research and Public Health, 17(8), 1-12. https://doi.org/10.3390/ijerph17082714

Kong, J. (2009). Effect of digital problem-based learning cases on student learning outcomes in ophthalmology courses. Archives of Ophthalmology, 127(9), 1211-1214. https://doi. org/10.1001/archophthalmol.2009.110

Korstjens, I., \& Moser, A. (2018). Series: Practical guidance to qualitative research. Part 4: Trustworthiness and publishing. European Journal of General Practice, 24(1), 120-124. https://doi.org/10.1080/13814788.2017.13750 92

Kózka, M., Sega, A., Wojnar-Gruszka, K., Tarnawska, A., \& Gniadek, A. (2020). Risk factors of pneumonia associated with mechanical ventilation. International Journal of Environmental Research and Public Health, 17(2), 1-7. https://doi.org/10.3390/ ijerph17020656

Lincoln, Y. S., \& Guba, E. G. (1985). Naturalistic Inquiry. SAGE Publications.

Morrow, R., Rodriguez, A., \& King, N. (2015). Colaizzi's descriptive phenomenological method. In The Psychologist, 28(8).

O’Brien, B. C., Harris, I. B., Beckman, T. J., Reed, D. A., \& Cook, D. A. (2014). Standards for reporting qualitative research. Academic Medicine, 89(9), 1245-1251. https://doi. org/10.1097/ACM.0000000000000388

Osti, C., Wosti, D., Pandey, B., \& Zhao, Q. (2017). Ventilator-associated pneumonia and role of nurses in its prevention. JNMA; Journal of the Nepal Medical Association, 56(208), 461-468. http://www.ncbi.nlm.nih.gov/ pubmed/29453481

Pepito, J. A., \& Locsin, R. (2019). Can nurses remain relevant in a technologically advanced future? International Journal of Nursing Sciences, 6(1), 106-110. https://doi.org/10.1016/j. ijnss.2018.09.013

Polit, D. F., \& Beck, C. T. (2012). Nursing research, generating and assessing evidence for nursing practice. Wolters Kluwer Health.

Powell-Cope, G., Nelson, A. L., \& Patterson, E. S. (2008). Patient care technology and safety. in patient safety and quality: An evidence-based Handbook for Nurses. http://www.ncbi.nlm.nih. gov/pubmed/21328784

Powell-Cope, G., Nelson, A. L., \& Patterson, E. S. (2008). Patient Care Technology and Safety. In R. G. Hughes (Ed.), Patient Safety and Quality: An Evidence-Based Handbook for Nurses. Agency for Healthcare Research and Quality.

Samra, S. R., Sherif, D. M., \& Elokda, S. A. (2017). Impact of VAP bundle adherence among ventilated critically ill patients and its effectiveness in adult ICU. Egyptian Journal of 
Dewi, Y.S., et al. (2021)

Chest Diseases and Tuberculosis, 66(1), 8186. https://doi.org/10.1016/j.ejcdt.2016.08.010

Torres, A., Niederman, M. S., Chastre, J., Ewig, S., Fernandez-Vandellos, P., Hanberger, H., Kollef, M., Bassi, G. L., Luna, C. M., MartinLoeches, I., Paiva, J. A., Read, R. C., Rigau, D., Timsit, J. F., Welte, T., \& Wunderink, R. (2017). International ERS/ESICM/ESCMID/ ALAT guidelines for the management of hospital-acquired pneumonia and ventilator-associated pneumonia. European Respiratory Journal, 50(3). https://doi. org/10.1183/13993003.00582-2017

Vance, G., Koczen-Doyle, D., Mcgee-Mccullough, D., Kuzma, A.M., Butler-Lebair, M. (2010). Nursing Care in the Intensive Care Unit Setting: The Role of the Nurse in the ICU. In: Criner, G. Barnette, R., D'Alonzo, G. (eds) Critical Care Study Guide (pp. 225-238). Springer. 